\title{
La oscuridad, el silencio y el vacío' (Darkness, Silence and Emptiness)
}

Margarita Rojas G. ${ }^{2}$

Universidad Nacional, Costa Rica

\section{Resumen}

Se ofrece una interpretación general de Los detectives salvajes, de Roberto Bolaño, a partir del análisis de su estructura. Se estudian el juego, la oposición entre la lealtad y la traición y un efecto de verosimilitud basado en las repeticiones de las entrevistas. Se hace referencia a otras obras de Roberto Bolaño como Amuleto, Estrella distante y 2666.

\section{RÉSUMÉ}

On propose une interpretation générale de Los detectives salvajes, de Roberto Bolaño, fondée sur l'analyse de la structure du roman. De plus, on étudie le jeu, l'oposition entre loyaté et trahison ainsi que l'effet de vraisemblance produit par les répétitions des interviews. On fait allusion a d'autres ouvrages de Roberto Bolaño tels que Amuleto, Estrella distante et 2666.

\section{Abstract}

A general interpretation is proposed of Los detectives salvajes, by Roberto Bolaño, beginning with the analysis of its structure. Other aspects studied include games, the opposition between loyalty and betrayal, and verosimilitude based on repetitions in the interviews. Mention is also made of other works by Roberto Bolaño, such as Amuleto, Estrella distante y 2666.

Palabras clave:, literatura latinoamericana, novela, interpretación, Roberto Bolaño Mots-clés: littérature latino-américain, roman, interprétation, Roberto Bolaño Keywords: Latin American literature, novel, interpretation, Roberto Bolaño

1 Recibido: 26 de mayo de 2016; aceptado: 20 de octubre de 2016.

2 Escuela de Literatura y Ciencias del Lenguaje. Correo electrónico: mrojas@una.cr 
Yentoncesme dicuenta que algo había fallado en los últimos días, algo habíafallado en mirelación con los nuevos poetas de México o con las nuevas mujeres de mi vida,

pero por más vueltas que le di no hallé el fallo, el abismo que si miraba por encima de mi hombro se abría detrás de mí, un abismo que por otra parte no me atemorizaba, un abismo carente de monstruos aunque no de oscuridad, de silencio y de vacio, tres extremos que me hacían daño.

Roberto Bolaño

No es nuevo afirmar que Los detectives salvajes de Roberto Bolaño es una novela sobre la literatura ${ }^{3}$; ello explica muchos trabajos dedicados a temas como la metaficción o la literatura dentro de la literatura ${ }^{4}$. En muchos de los estudios, sin embargo, cuando se busca reconstruir el concepto de literatura propuesto por la novela, generalmente se trata de establecer a partir de citas explícitas de las intervenciones de los personajes o del narrador; no se analiza ningún otro plano del texto y se omite el estudio de los acontecimientos.

Este trabajo se basa en la constatación de esta carencia, porque de un texto narrativo no se puede obviar la materia narrada a expensas del discurso. El propósito, por tanto, es tratar de revelar la noción sobre la literatura gracias a la peculiar y específica articulación interna de los acontecimientos narrativos propios del texto.

La riqueza diegética de la novela - un sinnúmero de personajes en tres continentes a lo largo de treinta años-, se unifican bajo el signo de la investigación. Eso explicaría el título de «detectives». Se

3 Roberto Bolaño, Los detectives salvajes (1998), $3^{\mathrm{a}}$ ed. (Barcelona, Anagrama, 2003). Se citará a partir de esta edición.

4 Susanne Hartwig, por ejemplo, propone que «uno de los temas recurrentes de Los detectives salvajes, «es» la teoría de la literatura. Aquí, dos niveles lógicos se confunden, puesto que Bolaño escribe una novela en la que se habla del arte de novelar. Más aun: lo que se dice sobre los «real visceralistas» y sus lecturas, también se podría aplicar a la novela Los detectives salvajes de manera que los testimonios (la novela de Bolaño) son en sí mismos una obra «real visceralista», siendo el libro sobre el movimiento literario una parte del mismo. Esta autorreferencialidad constante es una parte del enigma de la novela», Susanne Hartwig, «Jugar al detective: el desafío de Roberto Bolaño», Revista Iberoamericana VII, 28 (2007) 55. 
trata de distintas indagaciones que se imbrican unas con otras y no necesariamente tienen que ser «míticas ${ }^{5}$. La primera sección de la novela se organiza a partir de la indagación personal del narradorprotagonista, Juan García Madero, quien busca su verdadera vocación; cuando la define, tropieza con Ulises Lima y Arturo Belano, quienes por su parte están empeñados en otra indagación, la de la poetisa Cesárea Tinajero y su revista Caborca. Esta segunda indagación se mezcla en la tercera sección con la persecución de Lupe por parte de unos maleantes, a lo largo del desierto del norte de México.

La segunda sección se puede leer como una búsqueda en la que los buscadores se convierten en el objeto de las preguntas al tiempo que son entrevistadores. Se trata de una larga serie de entrevistas a muchos conocidos y amigos de Lima y Belano años después de los hechos de las primeras pesquisas. Lo que se ofrece al lector son las respuestas a preguntas implícitas sobre los integrantes del grupo visceralista y esas respuestas dejan traslucir la búsqueda implícita de un entrevistador o varios, que no se revelan. A veces parece que Belano es el entrevistador, en otras ocasiones más bien se habla de él. Manuel Maples dice, por ejemplo: «Este joven Arturo Belano, vino a verme para hacerme una entrevista» (176); Joaquín Vázquez Amaral apunta: «No, no, no, por supuesto que no. Ese muchacho Belano era una persona amabilísima, muy culto» (203). Clara Cabeza, la secretaria de Octavio Paz se dirige a más de un entrevistador porque a lo largo de su respuesta repite: «No saben ustedes el trabajo que tenía», «No saben ustedes el titipuchal de cartas que recibía don Octavio» (501,

5 Varios críticos coinciden en definir las acciones a partir de la búsqueda; Grínor Rojo sintetiza la historia como la de una búsqueda de «su objeto querido y perdido. Ese objeto es (...) una poeta (...) que los antecediera (...) en la periferia de la periferia», Grinor Rojo, «Sobre Los detectives salvajes», en Espinosa H., Patricia (ed.), Territorios en fuga. Estudios sobre su obra (Santiago: Frasis editores, 2003) 66. Milene Hostettler Sarmiento relaciona la búsqueda con La odisea y con el vacío: «la búsqueda lleva implícita la pérdida o la carencia (de algo o de alguien); es decir: un vacío»; "se presentan varias búsquedas paralelas y superpuestas», Milene Hostettler Sarmiento, «Búsqueda, errancia y degeneración en Los detectives salvajes», en Augusta López B. y José M. López, eds., Roberto Bolaño. Estrella cercana. Ensayos sobre su obra (Madrid: Editorial Verbum, 2012) 132 y 146. 
subrayado de M. R. G.); también a Amadeo Salvatierra lo entrevistan Ulises y Arturo. En general, la intención de las preguntas es reconstruir la historia del grupo realvisceralista después del primer año en México pues ya disuelto el grupo de los visceralistas, se convierte en materia de entrevista; para el filólogo, el último entrevistado cronológicamente, son su objeto de estudio, y él también de alguna forma, los está buscando en su investigación.

La complejidad del relato y su historia revelan una particular estructura: se interrumpe la historia principal, se corta el hilo temporal y la estructura temporal y la estructura espacial se hacen una con los narradores y los acontecimientos. Véase el cuadro $1^{6}$.

\section{Cuadro 1. Relación tiempo-narrador-acontecimiento}

\begin{tabular}{|c|l|l|l|}
\hline Sección & \multicolumn{1}{|c|}{ Tiempo } & \multicolumn{1}{|c|}{ Narrador } & \multicolumn{1}{c|}{ Acontecimiento } \\
\hline \multirow{3}{*}{ I } & 1) 2 nov 1975 & 8) JGM & 15) JGM se independiza \\
\cline { 2 - 4 } & 2) 31 dic 1975 & 9) JGM & 16) viaje al norte \\
\hline \multirow{3}{*}{ II } & 3) enero 1976 & 10) Amadeo Salvatierra & 17) conversación AS, UL y AB \\
\cline { 2 - 4 } & 4) dic 1996 & 11) E. García Grajales & 18) negación de JGM \\
\cline { 2 - 4 } & 5) enero 1976 & 12) Amadeo Salvatierra & 19) conversación AS, UL y AB \\
\hline \multirow{2}{*}{ III } & 6) 1 ene 1976 & 13) JGM & 20) viaje al norte \\
\cline { 2 - 4 } & 7) 15 feb 1976 & 14) JGM & 21) viaje al norte \\
\hline
\end{tabular}

$\mathrm{AS}=$ Amadeo Salvatierra; UL = Ulises Lima;

$\mathrm{AB}=$ Arturo Belano; JGM = Juan García Madero

La estructura genera un movimiento «hacia adentro»: los segmentos exteriores, I y III, son narrados por el mismo personaje; este, sin embargo, resulta negado en la sección del centro, $\mathrm{II}^{7}$. Con esto se pueden relacionar tres aspectos de la estructura temporal de Los

6 Felipe Ríos propone que «El trabajo de Bolaño con el tiempo, entendido como un viaje hacia el caos y la percepción de «desfases» en la estructura cronológica, estará desarrollado con gran audacia en Los detectives salvajes», Felipe Ríos, «Las jornadas del caos», Revista Iberoamericana 23,3 (2012): 66 .

7 M. Areco habla de que «la novela vuelve, como encerrándose en las vueltas de un (sic) espiral hacia adentro», Macarena Areco, «Las ciudades, los tiempos, las trayectorias y los géneros de Los detectives salvajes», Anales de Literatura Chilena 10, 11 (2009): 224. 
detectives salvajes. Primero, así como se entremezclan las indagaciones, sucede también con el transcurrir del tiempo. Los hechos de la I y III secciones ocurren a mediados de la década de 1970 y siguen un orden cronológico: la primera va del 2 de noviembre al 31 de diciembre de 1975; la tercera del 1 de enero de 1976 al 15 de febrero de 1976. Los siguientes veinte años se articulan a lo largo de la serie de entrevistas de la segunda sección, que empieza en enero de 1976 y finaliza en diciembre de 1996. De esta manera se empieza y se finaliza en los años setenta y el futuro se introduce en medio de estos como si, desde el punto de vista del relato, el futuro estuviera contenido dentro del pasado. Dicho de otro modo, las tres secciones hacen que el tiempo realice un movimiento envolvente desde los bordes hacia el centro de modo que pareciera que el relato literario se cierra sobre sí mismo en un movimiento contrario al desarrollo cronológico del tiempo ${ }^{8}$.

Con respecto a los narradores, también se crea una estructura similar. En los cuadros cuyo narrador es García Madero de la sección I y la sección III, contrastan con el cuadro central 11, cuyo narrador es el investigador García Grajales, cuando niega la existencia de J. García Madero.

Esa estructura temporal parece tener equivalencia en el tipo de espacios predominantes. Los acontecimientos centrales de la historia de los real visceralistas ocurren en la primera parte todos dentro de la ciudad de México; esta encierra los demás: casas, edificios, calles, cafeterías. En la segunda sección, los personajes viven en varios países y ciudades, incluida África, un ámbito más grande, el mundo. En la tercera sección el principal lugar es el desierto, que alberga varios pueblos y ciudades. Se trata, entonces de espacios distintos, ciudad, mundo y desierto, que comparten el rasgo de ser envolventes, exteriores y vastos.

8 El tema del análisis de F. Ríos es un día, el 1 de enero de 1976, que considera un «día invisible» pues «abre un abismo en el universo», día que «se constituirá como un «agujero negro»; el «día invisible» provoca que pasado, presente y futuro sean tres caras simultáneas de un solo evento cuadrimensional, donde los acontecimientos no tienen principio, medio o final; Ríos, 70. 
En el episodio de la invasión a la universidad por los militares, que también se desarrolla en Amuleto, mientras Auxilio Lacouture permanece encerrada en el baño un soldado entra y ocurre algo extraño con el tiempo: «se produjo un silencio especial, como si el tiempo se fracturara y corriera en varias direcciones a la vez, un tiempo puro, ni verbal ni compuesto de gestos o acciones» (193-194). De manera similar varios espacios de la primera sección comparten ese rasgo peculiar: son espacios «dobles» pues casi todos poseen otro espacio, interno y casi secreto. Dentro de las azoteas de varios edificios, por ejemplo, hay otras casas pequeñas, como donde vive Ulises Lima, de menos de 10 metros cuadrados, solo tiene un colchón, una silla y una mesa pequeña; también donde vive la familia de Pancho Rodríguez, de dos habitaciones para tres hermanos y la madre. En el interior del bar La encrucijada veracruzana hay una bodega y un baño, en donde García Madero encuentra a Belano y Lima fumando tanta marihuana que no les ve la cara sino solo una nube de humo; allí lo llaman por primera vez «poeta García Madero»; también en ese lugar el joven tiene su encuentro sexual con Brígida, una de las camareras. Detrás de la casa de la familia Font hay una casa pequeña, de dos pisos, compartida por las hermanas Angélica y María para recibir a sus amigos y sus parejas. Todos estos son espacios pequeños y semiescondidos, que se hallan dentro de otros más grandes.

Además, el desierto cobija los pueblos y dentro de uno de estos está el espacio más intrigante: el cuarto donde vivió Cesárea Tinajero cuando trabajaba en la fábrica de conservas. Dos veces la visita allí su amiga la maestra Flora Castañeda, la segunda vez alrededor de 1945. El cuarto está en una calle de un pueblo pequeño, Santa Teresa, al norte de México, en un lugar «pobre y abandonado», en «la cloaca a donde iban a dar todos los desechos de Santa Teresa», una calle con prostíbulos y bares (594). En el cuarto había más de veinte cuadernos de tapas negras, otros enseres y una navaja con la palabra «Caborca» grabada en la hoja (596), que es también el nombre de la revista que andan buscando Lima y Belano. 
Cesárea se muestra como una persona extraña: su risa se sobrepone a otros ruidos y llega hasta la calle, dominada por un repentino y total silencio (596). Además, había elaborado un plano detallado de su lugar de trabajo; habla del futuro, del año 2666 - que es el título de la novela póstuma de Roberto Bolaño-; hace y deshace las listas de lecturas para niños; cuenta que está escribiendo sobre Hipatía, un personaje antiguo.

Aunque el cuarto estaba «limpio y ordenado», «algo emanaba de él» y a la amiga «le pesó en el corazón»: «algo más sutil, como si la realidad, en el interior de aquel cuarto perdido, estuviera torcida, o peor aún, como si alguien, Cesárea, ¿quién si no? hubiera ladeado la realidad imperceptiblemente, con el lento paso de los días. E incluso cabía una opción peor: que Cesárea hubiera torcido la realidad conscientemente» (595)9.

La estructura topológica - espacios escondidos dentro de otros espacios - corresponde a la «forma» del tiempo, y produce el mismo efecto del envolvimiento temporal causado por la estructura de las tres partes (cfr. infra). Los espacios dobles, además, también corresponden a los personajes dobles: Ulises Lima - que tiene otro nombre- y Arturo Belano, actúan casi siempre juntos; Amadeo Salvatierra se da cuenta de que piensan y hablan entre los dos, como si fueran uno; además, ambos aman a una Laura, Laura Damián y Laura Jáuregui respectivamente. Hay dos hermanas Font y ambas son poetas; Horacio Guerra, <es> «el número uno de la Facultad de Filosofía y Letras, un pendejo llamado Horacio Guerra que es, sorpresa, el doble exacto, pero en pequeñito, de Octavio Paz, incluso en el nombre» (569).

\section{Eros y literatura}

Simultáneamente a la búsqueda-aprendizaje de la literatura, García Madero empieza su vida sexual; así lo escribe en su diario cuando cuenta acerca de sus primeras experiencias sexuales: la decisión de

9 Un espacio que esconde algo desconocido o secreto y desagradable aparece también en la novela Estrella distante: en su apartamento, el aviador Wieder organiza una exposición de fotos de mujeres torturadas y muertas, una exposición semisecreta, que sus invitados deben mirar de uno en uno. 
dejar los estudios de derecho por la poesía coincide con el abandono de su hogar para ir a vivir con una mujer, la camarera que lo inicia en el sexo ${ }^{10}$. A esta sigue una intensa relación con María Font, a quien traiciona con Lupe, amiga de María y prostituta. Durante esos años del grupo, el sexo es indisoluble del grupo de parejas de los realvisceralistas, lo experimentan al mismo tiempo que el aprendizaje de la literatura y es el móvil de la persecución de Lupe por Alberto, hasta el asesinato. De esta manera se plantea una primera equivalencia entre la práctica de la escritura literaria y la sexualidad: la búsqueda de la pareja parece equivalente a la búsqueda de la literatura.

En Los detectives salvajes, los aprendices de escritor procuran cambiar una vieja semiosfera literaria dentro de cuya periferia buscan a Cesárea; encontrarla, significa sustituir el centro —ocupada por Octavio Paz - por otro escritor. Algunos investigadores han entendido a la poetisa como la «gran musa»; otros hablan de la precursora o bien como la «madre mitológica del movimiento»; sin embargo, el mismo texto propone una red interrelaciones, equivalencias y oposiciones internas entre algunos personajes femeninos que vuelven equivalente literatura y la sexualidad ${ }^{11}$.

Cesárea Tinajero se precisa lentamente en la larga, paciente y metódica indagación de Arturo y Ulises. Para ello interrogan a dos amigos de ella - Amadeo Salvatierra y una maestra que la visitó-, y encuentran otras pistas en los periódicos de las bibliotecas de los pueblos de los desiertos. La información que les da Amadeo aparece en el relato de la visita de Belano y Lima al apartamento de Amadeo en el D. F., en trece fragmentos intercalados con otros a lo largo de la

10 La misma tesis sobre la relación entre literatura y sexo postula Igor Venegas De Luca en el artículo: «La caída de García Madero y el surgimiento del último detective: una propuesta de lectura en los detectives salvajes de Roberto Bolaño» Revista de Humanidades, V, 1920 (2009): 7995.

11 La significación de cualquier elemento textual no debería buscarse en teorías externas, como el psicoanálisis, como hace Grínor Rojo. Con el fin de entender la figura de Cesárea Tinajero no se la debe aislar sino más bien integrar dentro de la red de acontecimientos y temporalidades propias del recorrido textual. Por tanto, no debería bastar con decir que la novela es una parodia o una caricatura, ni de resolver el problema mediante el recurso a una definición de género literario. 
segunda sección. Se trata de un tipo de cronotopo ${ }^{12}$ que se desarrolla mientras toman mezcal Los Suicidas y tequila Sauza con botanas y conversan de literatura durante una larga noche. En el fragmento $n$. 11, que ocupa el centro de la novela, Salvatierra rememora a Cesárea y les muestra el único ejemplar de Caborca, del movimiento de poetas del realismo visceral, cercanos al estridentismo mexicano: «mientras bebía les iba leyendo trozos de aquel lejano año de 1921 y lo íbamos comentando, los párrafos y el mezcal, qué bonita manera de leer y de beber, despacio y entre amigos» (217-218).

El testimonio de la maestra amiga de Cesárea revela que la conoció muchos años después, que vivía en la calle Rubén Darío, que leía mucho y que escribía en un cuaderno muy grueso de tapas negras y en otro cuaderno que parecía un misal (594). Amadeo Salvatierra les cuenta sobre la poeta cuando era joven y también les muestra el único ejemplar de la revista Caborca. Haberla conocido antes y poseer más datos biográficos no sirve, sin embargo, al escribidor para lograr entender el poema-dibujo de la revista de Cesárea; este lo deben explicar los jóvenes al hombre.

La poetisa a quien recuerda Amadeo se contrapone a la que finalmente encuentran los jóvenes: el escribano la rememora como una atractiva secretaria que no tiene que ver con la gruesa mujer que vende hierbas medicinales y que se halla en los lavaderos públicos: «Vista de espaldas, inclinada sobre la artesa, Cesárea no tenía nada de poética. Parecía una roca o un elefante. Sus nalgas eran enormes y se movían al ritmo que sus brazos, dos troncos de roble, imprimían al restregado y enjuagado de la ropa. Llevaba el pelo largo hasta casi la cintura. Iba descalza» $(602)^{13}$.

12 Este tipo de cronotopo está descrito a partir de ejemplos de la literatura universal de varias épocas en Flora Ovares y Margarita Rojas G., «In vino veritas», Taller de Letras 29 (2001): 87-98.

13 Algunos consideran que el personaje se refiere a la poetisa mexicana Concha Urquiza (México 1910-1945), quien falleció ahogada en Baja California a los 35 años, junto con un compañero de excursión. Susanne Hartwig analiza el apellido Tinajero como una metáfora de la novela. Es posible establecer otras relaciones, que surgen del mismo texto; el nombre refiere, además del ámbito médico, a varias ciudades de la antigüedad romana de distintas regiones (Hartwig, ver nota 4). 
La Cesárea del final es una imagen degradada de la Cesárea poetisa, joven y musa. Lo anterior se percibe mejor si se compara con Lupe, la joven que anda con Juan. Ambas experimentan un proceso de degradación y ambas están lejos del ideal estándar femenino: una es una gruesa lavandera descalza y la otra una mujer oportunista que vende su cuerpo por dinero y cuyo novio es un delincuente. Las dos han abandonado la educación: Cesárea porque además de dedicarse a la poesía había sido maestra, Lupe había abandonado los estudios universitarios de danza para convertirse en prostituta. Además, Lupe había sido la amante del padre de su amiga, mientras que Cesárea había vivido en un cuarto de una calle del pueblo de Santa Teresa con prostíbulos y bares, no «una calle recomendable para una mujer decente» (594).

Por otro lado, en Los detectives salvajes hay otro personaje que se parece a Cesárea Tinajero. Se trata de Auxilio Lacouture, una joven uruguaya que se presenta a sí misma como «la madre de los poetas mexicanos». Su relato se amplía en otro relato de Bolaño, Amuleto, que se publicó un año después de Los detectives salvajes. Ambas, como se vio, se relacionan con los espacios escondidos y el fenómeno de la distorsión del tiempo.

El aprendizaje literario de Juan y sus amigos realvisceralistas es un viaje por varias zonas del mundo literario y sus múltiples dimensiones: los robos en las librerías, sus dueños; las revistas y sus títulos; la tipología homosexual de los poetas; el recorrido por las librerías, los talleres, los concursos y las presentaciones de libros, los juegos sobre retórica antigua, los contactos de escritores contemporáneos como Carlos Monsiváis, Octavio Paz y Manuel Maple Arce ${ }^{14}$. Todo lo anterior construye un mundo, que podría entenderse como una

14 Entre los nombres de las revistas y de las librerías están: Caborca, La batalla del Ebro, Rebeca Nodier; Lee H. Oswald; Plinio el joven, Lizardi, Mexicana, Horacio, Orozco. Juan ofrece una lista de libros que roba en cada una (102-103). Incluso la decoración del baño público El amanuense azteca hay un mural con «»un indio pensativo escribiendo en una hoja o en un pergamino» (119). 
semiosfera, según Iuri M. Lotman, la semiosfera de la literatura ${ }^{15}$. En la novela esta se encarga de dar sentido literario a todo; su centro debería ser la figura literaria —un escritor, su obra-, que en un momento histórico determinado ordena, jerarquiza y estructura el resto del espacio literario: en aquellos años en México el centro lo ocupaba Octavio Paz y contra él reaccionan los realvisceralistas.

Las semiosferas son mundos de sentidos; lo no literario permanece fuera, no tiene sentido, de ahí la dinámica entre la ficción y lo real. En Los detectives salvajes, se integran en la red de acontecimientos «inventados» - para el lector- otras obras literarias que ya forman parte de la «realidad real»; es un mecanismo que crea un efecto de sentido realidad: la literatura incorpora personajes de la historia y así adquiere una tonalidad verosímil ya que el tiempo histórico se vuelve parte del mundo literario, se otorga carácter de realidad al mundo literario, generalmente comprendido dentro de lo «ficticio».

Esta novela delimita la semiosfera literaria de varias formas; en primer lugar, contiene toda la literatura posible, la del pasado y la del futuro, la propia y la ajena. Así se explican las referencias internas del texto a otros textos del mismo autor -Estrella distante (1996), Amuleto (1999) - y también 2666, que no se publicó sino hasta 2004. En Estrella distante (1996) es el relato de otra búsqueda, la de la verdadera identidad del traidor y su búsqueda en Europa, a cargo de un exdetective - Romero- quien no desiste sino hasta acabarlo. El traidor es un personaje, Carlos Wieder, que se introduce en el taller de los poetas universitarios. Entre estos hay dos personajes que se parecen a las hermanas Font de Los detectives salvajes, las dos hermanas Garmendia, así como el narrador y su amigo, que son poetas, y asisten a dos talleres

15 Según Lotman, una semiosfera posee dos rasgos básicos: es irregular y está delimitada. Esto último significa que es un modelo «espacial» y un «continuum». El carácter espacial, sin embargo, no elimina su carácter abstracto si bien no metafórico. La principal tarea de una semiosfera, agrega el semiótico ruso, es limitar la penetración, filtrar y transformar lo externo en interno, dar sentido y transformar lo no semiótico en información. Las semiosferas tienen, además, una forma definida: poseen una frontera, una zona periférica y un centro o núcleo: en este están los sistemas semióticos dominantes mientras que en la periferia se hallan los catalizadores o traductores, Iuri M. Lotman, «Acerca de la semiosfera» (1984), La semiosfera (Madrid: Cátedra, 1996) 21-42. 
liderados por dos poetas amigos. En Los detectives salvajes Cesárea le había conversado a su amiga la maestra sobre el futuro, sobre el año 2600 (596) lo cual constituye una referencia a la última novela de Bolaño titulada 2666. Esta inicia también con la historia de la búsqueda de un escritor por cuatro filólogos, quienes se ocupan, en distintos países europeos e idiomas, de conocer exactamente la identidad del primero, afanes que los llevan hasta el norte de México, es decir, el mismo lugar donde termina la historia de Los detectives salvajes.

\section{Literatura y verosimilitud}

La referencia a datos literarios de una realidad externa al texto - por ejemplo, la historia o los libros del autor- son recursos para construir una nueva realidad dentro de la literatura. Con este mismo propósito se utilizan otros tipos de textos: además del diario, el juego y las entrevistas. Estos refuerzan la verosimilitud de distintas formas: es necesario recordar que mientras se dedicaba a narrar las historias de sus nuevos amigos en su diario, García Madero también dejaba traslucir la suya aunque de un modo menos visible. Su voz cuenta las pequeñas peripecias cotidianas del grupo de adolescentes en la ciudad de México, casi todas vinculadas con el oficio de la literatura. Él es un aprendiz de poeta pero también un erudito de retórica: le gustan jugar con los términos de la retórica clásica, adivinanzas y dibujos. En el sistema lúdico, el jugador pertenece simultáneamente a dos planos: uno es el ficticio, dentro del que acepta las reglas lúdicas y que coexiste con el otro plano, el de la realidad ${ }^{16}$.

En las entrevistas de la segunda sección a veces se establece una dinámica particular que consiste en la reconstrucción colectiva de los acontecimientos mediante las intervenciones de varios personajes. De esta forma la fiabilidad del recuerdo personal se supera mediante un esfuerzo colectivo. Así sucede con el duelo entre el crítico y el escritor

16 Hartwig analiza el nivel lúdico de la novela, incluidos los dibujos; Hartwig, 64 y 65. 
en la playa catalana; una amiga de Arturo Belano, Susana Puig, testigo del hecho, cuenta primero pero lo deja inconcluso, fragmentado; a continuación Guillem, uno de los padrinos, lo amplía, incluye más detalles. El gesto narrativo revela, por un lado, una particular concepción de la memoria: de un acontecimiento, cada individuo recuerda partes pero no la totalidad, por lo que se hace necesario la intervención de otros para poder completarlo, para rectificarlo. Por otro lado, al incluir varias voces, el texto se autopropone como más verosímil, ya que al ofrecer más de una perspectiva del mismo hecho aparenta ofrecer una mayor cobertura.

\section{El traidor}

La búsqueda de Ulises y Arturo finaliza al mismo tiempo que la búsqueda de Lupe por parte de Alberto; es un doble desenlace violento en el que pierden Belano y Ulises: estos se quedan en el desierto a enterrar los tres cadáveres, no logran leer los papeles de Cesárea y posiblemente sean buscados por la policía. García Madero, por el contrario, salva su vida, se deja el Impala, permanece con Lupe en la casa de Cesárea y se deja los cuadernos de la poetisa. Él es el triunfador pero a costa de los demás; sus últimas acciones lo revelan como un oportunista y vividor que desde el inicio, sin embargo, ha mentido y se ha aprovechado de sus parejas y sus amigos de varias formas y gracias a sus múltiples y solapadas traiciones.

La traición plantea la existencia de dos planos: frente a lo real y verdadero, está lo falso y lo oculto, que ante los demás aparenta ser lo contrario. A pesar de que todos lo han acogido, el joven - huérfano, poeta inexperto y novel amante - no se comporta lealmente con ninguno; se aprovecha de varios amigos, es un vividor, que se sirve de los demás para su beneficio; por su deslealtad, se opone a la leal Auxlio Lacouture. Con las mujeres tiene una actitud doble: después de vivir en la casa de unos tíos, a los cuales miente respecto a sus estudios; vive en la casa de Rosario, que ella paga con su trabajo de camarera en el café Encrucijada Veracruzana. Siendo pareja y conviviente de ella, se 
hace novio de María Font; del padre de esta recibe plata cuando anda con ella; se junta con Lupe cuando esta era la amante de Quim. Con los amigos se comporta de forma similar: los traiciona, se queda con el auto de Quim y con la obra de Cesárea pues no se las manda a Ulises y Arturo; pareciera que los acusa a la policía del estado, se apodera de la mitad de la plata que les da el padre de Laura Damián; aprovecha con Lupe la muerte de Cesárea para quedarse en su casa, y no les ayuda a sus amigos con los tres cadáveres. Lupe es parecida a él pues también se vale de estas circunstancias —el auto, la plata, la casa de Cesárea-, después de que todos la ayudan a librarse del chulo Alberto.

Juan justifica su proceder el 8 de febrero en su diario, el último acto de traición hacia sus amigos: «He leído los cuadernos de Cesárea Tinajero. Cuando los encontré pensé que tarde o temprano los remitiría por correo al DF, a casa de Lima o de Belano. Ahora sé que no lo haré. No tiene ningún sentido hacerlo. Toda la policía de Sonora debe ir tras las huellas de mis amigos» $(607)^{17}$.

La conclusión de la búsqueda de Cesárea es uno de los finales de la historia pero no el único pues, después de las muertes, García Madero sigue escribiendo todavía en su diario y agrega la imagen del último cuadrado y el último renglón del diario. Además, la historia de los visceralistas se prolonga muchos años más, hasta la investigación del filólogo Grajales, cuyo testimonio cerraría otra vez la historia del grupo. Los dibujos finales forman parte de los juegos de Juan y sus amigos; su significado puede revelarse si se interpretan contextualmente, es decir, por el lugar en el que aparecen dentro del texto. Juan García Madero, y no quienes los buscaban, es quien logra leer todos los cuadernos de Cesárea, según el diario del 8 febrero ${ }^{18}$. La anotación del día siguiente es la última antes de incluir la lista de pueblos (del 10 al 12 de febrero)

17 Uno de los rasgos que caracteriza la narrativa de los escritores del '50 es la oposición entre lealtad y traición. Para un análisis de las diversas formas que adopta la traición, cfr. el capítulo Margarita Rojas G., «Lealtad y traición», La ciudad y la noche (San José: Farben, 2006) 168-180.

18 «He leído los cuadernos de Cesárea Tinajero. Cuando los encontré pensé que tarde o temprano los remitiría por correo al DF, a casa de Lima o de Belano. Ahora sé que no lo haré. No tiene ningún sentido hacerlo. Toda la policía de Sonora debe ir tras las huellas de mis amigos» (607). 
y los tres cuadrados de juego (del 13 al 15 de febrero). En esa última anotación lamenta que Lupe crea que la policía no los buscará a ellos como asesinos. Entonces, cuando ya ha conocido a Cesárea y esta ha muerto, es decir, cuando ha finalizado la búsqueda, decide terminar de escribir poniendo como final de su diario una lista de pueblos y una última adivinanza con dibujos. Esta conclusión podría interpretarse como el reconocimiento de que ya no tiene nada sobre qué escribir, es decir, que ha perdido el motivo de su escritura ya que las indagaciones han acabado. Su diario empezó con la búsqueda de la literatura y la mujer, y acaba cuando se han conseguido ambas. El escritor del diario deja de anotar sus resúmenes diarios, los clausura y desaparece pues su tarea finaliza, como sujeto de su diario, es decir, de su enunciado. A él seguirá el filólogo o historiador quien, como también anticipa el texto, trata de descifrar la novela al igual que un jugador trata de adivinar el último dibujo, el del cuadrado vacío del segundo final ${ }^{19}$.

Sin embargo, ese dibujo también concuerda con la imagen de la ventana que aparece al final de la larga conversación entre Ulises, Arturo y Amadeo:

[Habla Amadeo] Y el que leía levantó la vista y me miró como si yo estuviera detrás de una ventana o como si él estuviera al otro lado de una ventana (...) luego los miré a ellos y los vi como estuvieran al otro lado de una ventana, uno con los ojos abiertos y el otro con los ojos cerrados, pero los dos mirando, ¿mirando hacia afuera?, ¿mirando hacia dentro? (...) Entonces yo me levanté (me crujieron todos los huesos) y fui hasta la ventana que está junto a la mesa del comedor y la abrí y luego fui hasta la ventana de la sala propiamente dicha y la abrí y luego me arrastré hasta el interruptor y apagué la luz (554).

19 La interpretación aquí propuesta de los tres últimos dibujos no se contradice con la de S. Hartwig quien afirma que el primer dibujo «muestra una estrella detrás de una ventana», el segundo «una sábana blanca detrás de una ventana, la adivinanza del tercer dibujo es el mismo marco de la ventana. El último dibujo ya no trasforma el contenido de la imagen en enigma, sino el marco y el acto de enmarcar» (Hartwig, 67); el marco y el acto de enmarcar pueden entenderse como una figuración de la enunciación. 
Lo anterior se expresa en 1996, cronológicamente correspondiente al último acontecimiento. La primera indagación sobre los realvisceralistas se narra en el diario del joven que se integra al grupo; él, además, es la fuente original de la narración de las búsquedas. Sin embargo, al final el texto lo desconoce: la investigación de García Grajales, que formará parte de una probable historia de la literatura, no lo incluye entre los participantes de la Historia. La novela anticipa su propio futuro con la negación de la existencia de su narrador de parte del investigador y este es el último acontecimiento en el tiempo cronológico. Con ironía el texto se niega a sí mismo: lo que el Lector ha leído proviene de un autor no existente.

Esa autonegación se refuerza semánticamente con la muerte de Cesárea justo cuando los jóvenes finalmente la han encontrado después de un largo recorrido. La poetisa desconocida y buscada, que podría haber constituido el centro de una nueva semiosfera literaria, cuando finalmente aparece, no solo no es la musa esperada sino que resulta asesinada por estos. De esa forma, el centro de la nueva semiosfera de la literatura queda con un centro vacío. Tal carencia da pie a la posibilidad de un intruso un escritor verdadero o bien, un advenedizo. En el texto, la literatura queda en manos del traidor, del escritor del diario: él se queda con la casa de Cesárea y es el único que lee los manuscritos de ella. El «final» del sentido podría leerse como que el fin de la Literatura: esto es lo que significan ambos finales, Cesárea muere y Juan García Madero no existe.

En el diario de García Madero, la anotación del día siguiente es el último texto de la historia; lo que sigue es una lista de pueblos y tres cuadrados de juego, con estos se cierra el texto. Las adivinanzas son un desafío para el Lector y el final en general es un desafío para la interpretación: ¿por qué termina así esa larga relación de hechos?, es decir, ¿por qué una narración renuncia a finalizar como tal? Siendo que el Lector está leyendo la conclusión de un largo viaje y este ha acabado con el hallazgo de los libros y unas muertes, los dibujos solo podrían significar que el autor del diario ya no tiene nada más 
que decir, que está vacío. Una vez que la persecución termina con la muerte de sus perseguidores y ha conseguido leer la obra buscada por todos, se le acaba la materia sobre qué escribir, por eso únicamente agrega nombres de pueblos y más adivinanzas. Esto ya lo ha hecho con anterioridad García Madero; es, además, un modo de mostrar su voluntad de suspender la anotación de sus resúmenes diarios, clausurarlos, dejar de hablar de sus propios acontecimientos: al dejar de existir como sujeto de su enunciado, solamente permanece la enunciación, el marco vacío. De esta manera el relato configura dos finales: (a) el último cuadrado y (b) el último renglón del diario.

Podría decirse que García Madero hubiera no podido trasmitir en su diario nada de los cuadernos de Cesárea Tinajero simplemente porque ella no escribió nada interesante. Según el testimonio de su amiga la maestra parece que la poetisa hacía algunas cosas sin sentido, sin congruencia: dibuja el plano de la fábrica donde trabaja pero no se entiende para qué; hace y deshace las listas de lecturas recomendaciones para la enseñanza, posee una extraña forma de reírse, dice que escribe sobre Hipatía pero no queda registro de eso. García Madero, el triunfador al final de las indagaciones, es el escritor desleal, un personaje casi oculto: entre los escritores que aparecen en la novela algunos se dedican a la búsqueda de otra escritora y de todo esto se entera el lector a partir de los apuntes de un tercer escritor. La atención se concentra en Cesárea Tinajero y se esconde la importancia del escribidor, de García Madero, el que documenta al margen los hechos de todos los demás.

En el diario, una hábil manipulación de su escritura lo esconde tras la máscara del neutro observador de los acontecimientos. Asume implícitamente el papel de espectador de las acciones de los demás y las presenta sin opinar o expresar sus sentimientos: narra como si fuera una cámara o un espejo que únicamente reproduce las acciones y los diálogos de sus amigos. Por eso el lector del diario construye una imagen positiva del narrador-protagonista, probablemente la de un muchacho inexperto, tanto en la vida como en la literatura y el 
$\operatorname{amor}^{20}$. Entonces, a pesar de que todos los hechos de la historia principal resultan narrados a partir de su propio diario, veinte años después su existencia ha pasado a la oscuridad y por eso resulta negada por el investigador del grupo literario, E. García Grajales:

De Arturo Belano no sé nada. No, a Belano no lo conocí. A varios. No conocí a Müller ni a Pancho Rodríguez ni a Piel Divina. Tampoco conocí a Rafael Barrios. ¿Juan García Madero? No, ése no me suena. Seguro que nunca perteneció al grupo. Hombre, si lo digo yo, que soy la máxima autoridad en la materia, por algo será (...) Hubo un chavito de diecisiete años, pero no se llamaba García Madero. A ver... se llamaba Bustamante. Sólo publicó un poema en una revista fotocopiada que se hizo en el DF, no más de veinte ejemplares el primer número, además sólo salió ese número (551).

Este es el tiempo futuro en relación con los hechos narrados acerca del grupo: los que habían sido investigadores de la literatura se convierten en literatura, los jóvenes poetas se transforman en materia de investigación del estudio de un filólogo. Cuando este conversa con un interlocutor anónimo le aclara: «En mi humildad, señor, le diré que soy el único estudioso de los real visceralistas que existen en México y, si me apura, en el mundo. Si Dios quiere, pienso publicar un libro sobre ellos» (550). Esto se menciona en el último episodio, desde el punto de vista cronológico, de diciembre de 1996, y el penúltimo de la II parte. Al cabo del tiempo la presencia del autor del diario se borra, desaparece: veinte años después de los acontecimientos relatados, la identidad y la existencia misma de García Madero resultan cambiadas o negadas, a pesar de haber sido quien las consignó en su diario.

Ese sentido de vacío, desaparición y muerte se refuerzan con la decisión de empezar el relato el día de los muertos, de fuerte significación en la cultura mexicana, y terminar el último día del año: todo

20 En realidad, se trata de un pseudodiario ya que incluye diálogos y relatos de acontecimientos como en un relato normal. 
conduce a una isotopía semántica de la muerte o el fin. Recuérdese que cuando los amigos se van aproximando a Cesárea, se narra la muerte del torero, su velorio y entierro (579), con lo que se relaciona el hecho de que Cesárea escribió el epitafio de la tumba del torero así como el último dibujo de los juegos que son cuatro charros velando un cadáver (577). Hay otras referencias a la muerte: la de los poetas muertos al inicio, la temprana muerte de la joven poetisa Laura Damián; la muerte del general Diego Carvajal en el burdel; el mezcal Los suicidas que sirve Amadeo Salvatierra a Ulises Lima y Arturo Belano; el compañero de cuarto de este muere de cirrosis en un hospital catalán; la muerte del hijo del fotógrafo Emilio López Lobo; en África, según Urquenda, Belano anda buscando morir.

La muerte más importante, sin embargo, es la de quien pudo haber ocupado el centro de la nueva literatura - a que tratan de crear los jóvenes poetas-: Cesárea Tinajero, quien vivía en la calle Rubén Darío, muere a manos de los mismos jóvenes que la buscaban. $\mathrm{Su}$ casa y sus apuntes quedan en manos del autor cuya existencia, sin embargo, no será reconocida por los historiadores del futuro. 